\title{
Regime de Bem-estar Social no Brasil: Três Períodos Históricos, Três Diferenças em Relação ao Modelo Europeu Social-democrata
}

\author{
Regimen of social welfare in Brazil: three historical periods, three differences with the European social \\ democratic model
}

\section{Resumo}

0 regime de bem-estar social no Brasil pode ser comparado com o modelo social-democrata europeu em três períodos históricos, apesar das especificidades e diferenças que aqui adquiriu. No período 1930-1964, serão abordadas a importância da concepção de cidadania regulada para a definição de direitos sociais no Brasil e a comparação com o desenvolvimento da cidadania nacional e 0 papel dos sindicatos no welfare state na Europa. No período 1964-1985, será apresentada a forma como se estruturou a política social do regime militar, enquanto, na Europa, havia um ambiente democrático, com direitos sociais universais e participação social como bases do regime de bem-estar social. No período após 1985, com ênfase na fase da segunda reforma social iniciada pós-Plano Real (1994), será destacada a visão mais generosa e universalizante de direitos sociais. Para esse período, será importante apontar como, na Europa, nesse momento, se questionaram as bases materiais e a concepção do welfare state, visando, ao mesmo tempo, revisar alguns fundamentos para mantê-lo como padrão de solidariedade social.

Palavras-chave: cidadania; direitos; igualdade; democracia; desigualdade.

Eduardo José Grin - eduardo.grin@fgv.br

Bacharel em Ciências Sociais, Especialista em Sociologia, Mestre em Ciência Política, Doutorando em Administração Pública e Governo. Pesquisador do CEAPG. Professor-tutor da FGV On Line.

Artigo submetido no dia 10.06.2012 e aprovado em 01.05.2013

\section{Abstract}

The social welfare system in Brazil can be compared with the European social democratic model in three historical periods, despite the specificities and differences. The period of 1930-1964 will address the importance of the concept of citizenship regulated to the definition of social rights in Brazil and compare it with the development of national citizenship and the role of trade unions in the welfare state in Europe. The period of 1964-1985 will present the structure of the military regime's social policy while in Europe there was a democratic environment with universal social rights and soclal participation as the basis for the system of social welfare. The period after 1985, with emphasis on the second phase of social reform initiated after the Real Plan (1994), will highlight the more generous and universalizing vision of social rights. This period will be important to compare as Europe, at that time, questioned the material foundation and the design of the welfare state while aiming to review some grounds to keep it as a pattern of social solidarity.

Key words: Citizenship - Rights - Equality - Democracy - Inequality. 


\section{Introdução}

O debate sobre direitos sociais e regime democrático é um importante tema na agenda de construção da cidadania no Brasil. Mas será que a constituição da cidadania no Brasil inverteu a ordem, criando um sistema de direitos sociais antes de consolidar os direitos civis e políticos? Esse processo teria gerado o que Carvalho (2006, p. 221) chamou de estadania, fruto de "uma cultura orientada mais para o Estado do que para a representação [e] em contraste com a cidadania". Este artigo discute como, em perspectiva comparada com a experiência europeia do welfare state social-democrata, conforme Esping-Andersen (1990), ocorreu a evolução do regime de bem-estar no Brasil em três momentos distintos, a partir de 1930. Mais especificamente, comparam-se as duas realidades após a década de 1990.

Do ponto de vista dos tipos de welfare state propostos porEsping-Andersen (1990), neste texto, para fins da análise realizada, será compreendido como sinônimo do modelo mais universalista ou redistributivista. Essa forma de Estado de bem-estar social, típica dos países escandinavos, não se confunde com aquelas mais conservadoras (o caso francês ou alemão) nem como o modelo mais residual (o caso inglês ou americano). Welfare state, portanto, será utilizado para se referir ao modelo social-democrata proposto por esse autor. Torna-se possível, assim, comparar como essa concepção de Estado de bem-estar social e seu "tipo" mais avançado, em termos de direitos sociais, sofreram mudanças no Brasil e nos países europeus, que adotaram sob três ângulos opostos: a) sua inexistência no Brasil até 1988 , pois estava mais próximo do modelo conservador de regime de bem-estar social; b) a constituição de um sistema de políticas sociais no Brasil após a década de 1990, em bases mais universais; c) sua progressiva desconstituição como sistema público de direitos sociais em países europeus de matriz social-democrata.

O objetivo central do artigo não é gerar inferências analíticas, mas, sim, apresentar um quadro geral que, de maneira comparada, indique as inflexões nos regimes de bemestar no Brasil e na Europa. Nesse sentido, a dimensão essencial para gerar essa discussão é a forma como, nas duas experiências, as políticas sociais promovidas pelo Estado sofreram mudanças ao longo da sua evolução. No Brasil, as políticas sociais avançaram de um modelo mais restritivo para uma forma mais generosa de universalização de direitos após 1985. No caso clássico do welfare state de cunho mais universal que se moldou na Europa, o que se observou, no mesmo período, foi uma gradativa redução dessa oferta de políticas públicas.

Como se trata de um artigo exploratório, com suas finalidades de comparação, compreende-se que ele possui o limite de apresentar as semelhanças e diferenças entre o caso brasileiro e o welfare state clássico europeu. Está fora do escopo deste trabalho produzir inferências analíticas com base em variáveis políticas, sociais ou econômicas. O artigo visa, assim, contribuir com uma linha de análise comparada, para o que sugere alguns temas e questões que possam servir para constituir hipóteses para futuras pesquisas qualitativas e quantitativas. Como um ensaio amparado na literatura sobre o tema, a interpretação sugerida visa indicar a possibilidade de estudos comparados sobre os regimes de bem-estar social.

Por outro lado, o enfoque adotado para realizar a discussão da literatura busca 
vincular o desenvolvimento econômico com o desenvolvimento social e suas implicações para os direitos sociais. Não foram consideradas outras dimensões, como o desenho das instituições políticas ou a construção de pactos político-sociais dedicados a favorecer ou reduzir a universalidade dos regimes de bem-estar. No caso brasileiro, a Constituição Federal de 1988 ampliou sobremaneira o sistema de políticas sociais, e esse pano de fundo institucional foi adotado como variável de contexto para a promoção de políticas encetadas a partir da década de 1990. Compreende-se que já há vários estudos sobre o caráter "cidadão" da Constituição de 1988, o que tornaria pouco relevante inserir essa discussão no artigo. Para o caso europeu, considerando a tipologia clássica do welfare state nos termos de EspingAndersen (1990), além das possibilidades deste trabalho, estaria uma análise que comparasse suas instituições políticas e desenhos constitucionais. Isso porque seria necessário discutir as particularidades, sobretudo dos países escandinavos, que servem de referência para essa tipologia de welfare state.

A perspectiva de análise do artigo considera os argumentos de Marshall (1967, p. 87-88) sobre a construção da cidadania, tomando o caso inglês como exemplo. $O$ autor destaca os problemas que houve, pois "os direitos civis deram poderes legais cujo uso foi drasticamente prejudicado por preconceito de classe e a falta de oportunidade econômica". A estrutura social e econômica não favoreceu o exercício efetivo da igualdade formal atribuída ao cidadão. Enfatiza que o status de cidadão conferiu igualdade aos indivíduos, mas o sistema de classes sociais gerou desigualdades econômicas reais, contrarrestadas pelas lutas políticas da classe trabalhadora, visando ampliar o reconhecimento dos seus direitos civis e políticos.
Os direitos sociais, porém, voltados a atenuar desigualdades reais entre os cidadãos, só podem ser patrocinados pelo Estado, pois este possui funções reguladoras para incidir na questão do status formal de cidadão vs. situação real de classe, nos termos propostos por Marshall (1967). O desenvolvimento da democracia e as contradições entre o plano real e formal da cidadania demandam, assim, a intervenção estatal para equilibrar expectativas e possibilidades de inclusão social. Segundo Marshall (1965), portanto, as políticas públicas deveriam garantir um mínimo de serviços essenciais viabilizadores do status real da cidadania para os indivíduos poderem usufruir da herança social e econômica do país. O Estado deveria, pois, atuar na regulação da ordem social e garantir o mínimo para os indivíduos se inserirem na competição nas oportunidades econômicas. Ao fazêlo, intervém para reconhecer e estender direitos sociais.

Em resumo, os direitos civis igualam os indivíduos pela possibilidade legal de terem liberdades comuns. Os direitos políticos garantem aos indivíduos igualdade de participação na escolha do governo. Os direitos sociais definem um mínimo de igualdade, considerando a desigualdade econômica e de oportunidades. Responder a esse modelo de maneira integrada e aproximar as expectativas do cidadão da realidade social parece ser o desafio das democracias de massa europeias. No modelo de Marshall, isso confere um papel importante ao Estado e suas políticas públicas, além de alicerçar sua legitimidade política e social. 
Se esse mesmo modelo for utilizado para se analisar a evolução dos direitos sociais no Brasil, contudo, nada parece confirmar a mesma trajetória de desenvolvimento. Sobretudo, como será visto, houve um grande atraso histórico para o País se aproximar da trilha da universalização dos direitos. Antes de garantir direitos mínimos para amplas parcelas da população, criou-se um sistema que aprofundou a desigualdade social e a exclusão, pautado por incorporação meramente formal, ainda que legalmente amparada. Esse modelo, iniciado após 1930, ao se basear na estratificação funcional com base no mercado de trabalho, só fez ampliar os níveis de desigualdade real entre setores da sociedade. No Brasil, pelo menos até meados da década de 1980, o status formal de cidadão e sua situação social real alimentaram, assim, uma lógica marcada por baixos níveis de inclusão dos indivíduos. É sob esse enfoque comparado que o artigo aborda, considerando três períodos históricos, até o final dos anos 1990, como evoluíram os direitos sociais no Brasil e no modelo clássico europeu. A primeira parte trata dessa questão no período que se estende de 1930 até o golpe militar em 1964. Em seguida, discute-se o termo dos governos militares, que se encerrou em 1985. A última seção abarca a fase da retomada da democracia e avança até o início dos anos 2000.

\section{Cidadania Nacional e Cidadania Regulada: as Políticas Sociais no Brasil entre 1930-1964}

Reivindicar igualdade foi central na luta da classe trabalhadora europeia no século XIX. Para Bendix (1996), a oferta de educação pública e o direito de voto materializavam essas reivindicações e contribuíram para consolidar a cidadania nacional e a participação na comunidade política. No Brasil, com a exclusão dos analfabetos do direito de votar até 1985, não foi com a educação política pública universal que se constituiu a cidadania. Educação e direito de voto tiveram um peso menor na construção da "cidadania nacional" 2 .

$\mathrm{Na}$ Europa, sobretudo na Inglaterra, a expansão da indústria influenciou a ação política da classe trabalhadora em busca de direitos sociais. No Brasil, com a industrialização, apenas os estratos inseridos no mercado de trabalho tiveram direitos reconhecidos. Antes de universalização, houve a construção de uma comunidade política "regulada" pelo Estado e restritiva, ao conferir direitos como tradução da ocupação funcional no mercado de trabalho (SANTOS, 1979)3․ Não houve luta política dos "de baixo" para ampliar direitos, mas uma política das novas elites dominantes para criar uma cidadania limitada.

$\mathrm{Na}$ Europa, o operariado industrial lutou para garantir o direito de associação e de organização sindical (BENDIX, 1996). No Brasil, O Estado regulou o conflito social criando sindicatos dependentes legal e financeiramente. O "sindicato público" e a regulamentação da profissão foram os parâmetros legais da cidadania e de sua incorporação na comunidade nacional (SANTOS, 1979) ${ }^{4}$. A estratificação funcional legalizou as bases da cidadania regulada, e a sindicalização foi o meio para gerar o reconhecimento dos direitos da cidadania, que criou uma incorporação desigual ao controlar o acesso formal das massas trabalhadoras como cidadãos.

Para analisar como os países estruturam 
seus sistemas de políticas sociais, Haggard e Kaufman (2008) propõem o conceito de realinhamento crítico: cortes históricos e políticos que influem na trajetória posterior dos regimes de bem-estar. Esse conceito aplica-se ao Brasil para analisar os efeitos prolongados da cidadania regulada, pois ter profissão reconhecida e emprego formal foram requisitos para o reconhecimento de direitos sociais até a década de 1970. O seguro social derivado de contribuições dos assalariados, e não na previdência social como direito universal, foi a tônica (MARSHALL, 1965). A partir dos anos 1930, criaram-se as condições objetivas de políticas sociais estratificadas e dependentes da patronagem sindical e das lideranças políticas (HAGGARD; KAUFMAN, 2008). Com efeito, a cidadania nacional e os direitos sociais universais não embasaram esse realinhamento crítico.

Segundo Haggard e Kaufaman (2008), no Brasil, as políticas sociais serviram aos objetivos da elite dominante ao criar sustentação social nas cidades como lócus do emprego formal. A política social e a cidadania regulada não conflitavam com os padrões de acumulação para promover o desenvolvimento capitalista (SANTOS, 1979). Esse foi o eixo central do realinhamento crítico no pacto entre as elites dominantes e os sindicatos de trabalhadores urbanos pós-1930. Na Europa, o reconhecimento de direitos sociais foi produto da luta política e tornou-se universal. No Brasil, o custo das opções políticas, segundo Haggard e Kaufman, (2008), foram restrições em realocar recursos para os mais pobres.

Vincular acumulação desenvolvimentista, cooptação da classe trabalhadora urbana e política social estratificada foram os traços centrais no estado de bem-estar no Brasil de 1930 a 1964. Não houve relação entre democracia, participação eleitoral e políticas sociais. Tampouco se pode comparar o sistema corporativo brasileiro com o papel dos sindicatos no modelo clássico social-democrata de "parceria social" que aproximava relações industriais e representação de interesses (ESPINGANDERSEN, 2000). Mais distante ainda esteve o caso brasileiro do modelo socialdemocrata de sindicatos de trabalhadores assalariados que financiavam partidos trabalhistas na arena da política. Por serem maioria e terem seus próprios partidos, os trabalhadores seriam os grandes beneficiados com a ocupação de postos no Estado para implantar políticas de bemestar social (AMENTA; SKOCPOL, 1986). No Brasil, mesmo entre 1945-1964, e com o Partido Trabalhista Brasileiro atuando nos sindicatos de trabalhadores urbanos e a burocracia do Ministério do Trabalho, tal concepção não logrou ser o modelo.

Entre 1930-1964, teve início o processo de regulação social e intervenção do Estado para estruturar o regime de bemestar no Brasil (DRAIBE, 1994). Mas, a considerar a "lógica do industrialismo" e o welfare state como evolução social (Draibe; RIESCO, 2006), o Brasil teria que esperar um pouco mais. Gerou-se, contudo, uma síntese peculiar entre desenvolvimentismo, cooptação política dos sindicatos e restrições à democracia. Diferentemente da experiência europeia, a cidadania regulada foi o meio de incorporação à comunidade política e um modelo meritocrático-individual de solidariedade social. Associada ao corporativismo do mercado de trabalho, essa foi a solução conservadora para as políticas sociais (DRAIBE; AURELIANO, 1989). 


\section{Expansão e Consolidação do Regime de Bem-estar Social no Brasil (1964-1985)}

A consolidação do welfare state na Europa deu-se na década de 1960, ao universalizar direitos sociais (ESPING-ANDERSEN, 2000), e apoiou-se em governos democráticos e direitos civis dos cidadãos. Havia uma base econômica a sustentar a oferta de serviços sociais, amparada no pleno emprego para financiá-la. No Brasil, a consolidação e a expansão do regime de bem-estar social teve início, pós-1964, sob um governo autoritário. Não houve universalização dos direitos sociais, tampouco o respeito aos direitos civis, e um modelo econômico concentrador de renda e socialmente excludente financiou a ampliação da oferta de serviços sociais.

Para Draibe (1994, p. 271), as políticas sociais ancoraram-se no arrocho salarial, no cerceamento às organizações e na exclusão social. Havia um nexo entre regime político, padrão de acumulação capitalista e política social carente de critérios para universalizar direitos. A agenda social era subordinada à modernização da economia, no que Draibe (1994) chamou de "reforma conservadora" das políticas sociais pós-1974. O regime militar buscou equilibrar redução de despesas e ampliação de objetivos redistributivos ao "redescobrir" a pobreza (FAGNANI, 1997).

Para Santos (1979), compreender a política social do regime militar requer observar que a cidadania regulada se tornou incompatível para equilibrar crescentes demandas dos grupos sociais. "Em aparência e, novamente, como em 30, tratava-se de reformular as instituições em que se processavam a acumulação e a distribuição compensatória, e novamente opor via autoritária" (SANTOS, 1979 , p. 82). A alternativa autoritária, em
1964, derivou da incapacidade de equilibrar democracia, acumulação capitalista e conflito social. Essas rupturas institucionais e 0 desequilíbrio entre desenvolvimento econômico, demandas sociais e normalidade democrática não ocorreram na consolidação do welfare state na Europa após 1945.

Em 1964, economia, democracia e sociedade entraram em um descompasso incapaz de ser respondido pelo desenho político-institucional em vigor (DRAIBE, 1994). O regime militar, ao romper com as regras democráticas, buscou respostas à complexificação da estrutura social distintas daquelas voltadas a consolidar 0 welfare state na Europa, visando construir o Estado sem mobilização da sociedade. Não houve nada parecido com a "luta de classes democrática" entre sindicatos, partidos e governo como base política do welfare state europeu. $\mathrm{O}$ antagonismo entre expansão da economia e o desenho das políticas sociais foi resolvido de maneira conservadora (DRAIBE; AURELIANO, 1989).

As políticas sociais tiveram baixo impacto redistributivo, foram pouco inclusivas, tiveram restritos programas universais, carentes de seletividade e mal focados nas camadas mais necessitadas (DRAIBE, 2003; DRAIBE; AURELIANO, 1989). Distintamente do modelo social-democrata europeu, as políticas sociais do regime militar não foram universais e carregaram a herança da cidadania regulada e da estratificação ocupacional. Não se concebeu a política social como um direito e não se integraram participação social e democracia na construção da cidadania nacional. Se, até 1964, havia a cidadania regulada, no regime militar, os patamares de cidadania estiveram aquém do mínimo de justiça (SANTOS, 1979). 
A política social do regime militar foi constituída de maneira burocrática. Ao controle sindical, assim, somou-se o controle administrativo de salários sem a mediação da "luta de classes democrática." Mesmo programas como o Funrural, organizado sobre bases não contributivas e mais universalizante, foram implantados pela burocracia estatal. Não aceitando os conflitos políticos para gerar algum consenso social, o regime militar ampliou a centralização burocrática. Organizou-se um "regime de bem-estar burocrático" sem a política para expressar demandas sociais.

Para Draibe (1994), as estruturas centralizadas que coordenavam os programas sociais se repolitizaram com a crescente autonomia dos técnicos. A política representativa foi substituída pela "política burocrática" (LINDBLOM, 1981). Os "anéis burocráticos" legitimaram a burocracia para definir políticas sociais como interlocutores, sobretudo, perante grupos privados $^{5}$. Por exemplo, a ampliação da oferta de serviços de saúde favoreceu a rede privada em detrimento de políticas pública universais, como viria a ser o Sistema Único de Saúde após 1988.

Preservaram-se traços meritocráticosparticularistas, o viés corporativo e clientelista na concessão de benefícios (FAGNANI, 1997; DRAIBE; AURELIANO, 1989). Buscouse ajustar o convívio da cidadania regulada com a expansão dos serviços sociais. Para Draibe (1994, p. 305), "tais políticas tenderam a reproduzir e reiterar as desigualdades iniciais". Enquanto o modelo socialdemocrata se consolidava na Europa em bases universalizantes, aqui, os serviços sociais expandiram-se de maneira limitada para incidir sobre a desigualdade. $O$ caráter terminativo da educação técnica é um exemplo para reduzir a pressão das "classes baixas" por vagas nas universidades e reproduzir a ordem social por meio do ensino.

Um modelo mais compreensivo de bemestar social teve que esperar o período democrático iniciado em 1985, sobretudo pós-1994, como se discute abaixo.

\section{0 "Desencontro" entre o Estado de Bem-estar Europeu e o Brasil dos Anos 1990}

Para Esping-Andersen (2000), o welfare state passou a enfrentar novos problemas quando a economia pós-industrial deixou de garantir pleno emprego e igualdade. Mudanças no mercado de trabalho afetaram o trade-off emprego e igualdade, gerando instabilidade familiar e perda de integração social. Mesmo que o desenvolvimento histórico do estado de bem-estar tenha demonstrado que não há incompatibilidade entre capitalismo e cidadania, o padrão de solidariedade assentado no pleno emprego começou a ruir. Demandava-se rever o contrato entre o Estado e a sociedade para redefinir os novos riscos sociais a serem enfrentados, a despeito de não se questionar o princípio básico: os cidadãos têm direitos reconhecidos. Daí a importância de a "desmercadorização" ser uma política pública para disponibilizar serviços sociais como direito dos cidadãos, para que estes se mantenham sem depender do mercado. Com esse conceito, tem-se uma diretriz para avaliar a qualidade do regime de bemestar (ESPING-ANDERSEN, 1990).

Com as ameaças de desemprego estrutural decorrente da modernização tecnológica, porém, como criar bases econômicas para sustentar a "desmercadorização"? 
Se a nova economia de serviços amplia os empregos mal pagos, tal situação incide negativamente sobre a arrecadação dos governos. O modelo do pleno emprego, com políticas sociais de qualidade, e que ampara a "desmercadorização", tem novos desafios de financiamento para manter sua visão de solidariedade. Para o autor, a resposta para a pouca oferta do mercado seria as famílias buscarem meios alternativos de sobrevivência, apesar de o autor ser pouco claro sobre a forma como essa opção poderia se materializar e ser sustentável.

Esping-Andersen (2000) também argumenta que 0 desemprego pode opor insiders (homens) e outsiders (jovens e mulheres), enfatizando o risco, em longo prazo, de o welfare state conviver com desemprego, baixos salários e pobreza. Para o autor, 0 regime de bem-estar social consiste em reconstruir a "luta de classes democrática" e uma estratégia "ganha-ganha" para impedir a emergência de um modelo formado por insiders e outsiders. No equilíbrio proposto entre política e mercado, todavia, não fica claro se os sindicatos seriam, assim como na "era dourada" do welfare state, os atores privilegiados na relação com o Estado.

Comojá vimos, no Brasil, a cidadania regulada amparada no emprego formal embasou as políticas sociais, pelo menos, até meados dos anos 1970. O capitalismo no Brasil nunca buscou gerar um trade-off entre igualdade e emprego, mas, sim, regular as bases da acumulação capitalista. A reprodução do capital historicamente conviveu com exclusão social e baixos salários. Nunca houve, no Brasil, uma "luta de classes democrática", pois, como mostra a literatura (Santos, 1979; Draibe, 1994; Fagnani, 1997), políticas sociais altamente regressivas e baseadas na contribuição individual foram a tônica. Um sistema pouco afeto a ampliar a incorporação dos cidadãos para um padrão mais universal de solidariedade, ao menos até a segunda metade dos anos 1980, quando, lentamente, se iniciam mudanças nessa direção.

No caso europeu, ao abordar a pobreza, Esping-Andersen (2000) destaca as políticas públicas para protegê-la e evitar esse risco temporário e conjuntural. O desenvolvimento de habilidades familiares seria de enfrentar esse problema ${ }^{6}$. No Brasil, com será visto, a pobreza é tratada como uma mazela estrutural decorrente do padrão histórico do desenvolvimento capitalista. Nesse sentido, programas como "Bolsa Família" parecem não caber na concepção de Esping-Andersen (2000), pois são iniciativas de transferência de renda de sobrevivência familiar. Frise-se que, nesse caso, não se aplica o conceito de "desmercadorização", pois as famílias não estão diante da opção de se afastar do mercado de trabalho como um direito reconhecido. Tampouco se pode dizer que se trata de um programa temporário para atacar a pobreza. Nem mesmo se pode comparar o Programa Bolsa Família com um processo de "desfamiliarização", como frisado por EspingAndersen (2000), pois, entre os objetivos do programa, não há uma estratégia para que o Estado provenha serviços, como creches, que facilitariam a inserção das mulheres no mercado de trabalho, por exemplo. Em face da dificuldade de utilizar o modelo de EspingAndersen $(1990 ; 2000)$ na realidade brasileira, faz-se necessário um novo conceito. Desse modo, Draibe e Riesco (2006, p. 21) propõem que:

O enfoque de regimes de bem-estar social tem contribuído decisivamente para evitar os dois riscos [a generalização indevida e 
a redução historicista - grifos do autor] mais comuns em matéria de comparação histórica de complexos processos de desenvolvimento econômico e social.

Aanálise desses autoreséútil paracompreender o sistema de políticas sociais5 no Brasil depois de 1988, especialmente após o Plano Real, em 1994. O sistema de políticas sociais passou a ser visto pelo viés positivo de sua contribuição para o desenvolvimento econômico. O Estado constituiu-se no promotor de programas públicos para estimular um ciclo virtuoso entre economia e política social com a participação direta dos cidadãos (DRAIBE; RIESCO, 2006) para que a política social amplie a equidade (DRAIBE, 2003). Para Draibe e Riesco (2006, p. 13-14):

São os sistemas de políticas sociais ou, mais especificamente, o Estado de bem-estar, o ponto de partida da análise para articular o desenvolvimento econômico e a política social. Por mais que seja fragmentada a visão de um ou outro programa social, é a perspectiva do sistema de proteção social como um todo que possibilita examinar os efeitos dinâmicos da política social no tempo, acompanhando o mesmo tratamento dinâmico com que se examina o desenvolvimento econômico.

$\mathrm{Na}$ próxima seção, ver-se-á como essa concepção é útil para a análise do sistema de políticas sociais no Brasil após 1994.

\section{Sistema de Políticas Sociais e Desenvolvimento Econômico no Brasil Pós- 1994}

A partir de 1994, com o Plano Real já em vigor, gerou-se uma estratégia de desenvolvimento social baseada na universalidade, solidariedade, igualdade de oportunidades, participação, descentralização e associação com a sociedade civil. Os eixos estruturadores foram: reforma dos serviços sociais básicos públicos, melhoria na quantidade e qualidade das oportunidades de trabalho e obtenção de renda, ampliação das oportunidades de acesso a ativos produtivos como terra e crédito, iniciativas para aliviar, no curto prazo, a pobreza aguda e programas de melhora e transferência direta de renda. Essa arquitetura foi concebida com base na estabilidade macroeconômica, mas buscando proteger sua continuidade contra variações cíclicas do desempenho fiscal e orçamentário (FARIA, 2002)7 ${ }^{7}$ O sistema de política social foi, desse modo, concebido em bases mais universalizantes.

Nesse período, enquanto, na Europa, o desafio, segundo Esping-Andersen (2000), consistia em responder à crise do welfare state na economia pós-industrial, no Brasil, se avançava para um sistema mais generoso de políticas sociais. Ao mesmo tempo, a ampliação da democracia e a participação social passaram ser instrumentos-chave para, desde o final dos anos 1980, implantar as políticas sociais (DRAIBE, 1998). Essa engenharia institucional possui duas distinções em relação ao modelo "Estado, Mercado e Família" de EspingAndersen (2000) ${ }^{8}$ : a) a participação da sociedade civil por meio de Organizações Não Governamentais (ONGs) e outros tipos de parceria e; b) a descentralização de políticas públicas, que não é abordada como forma político-organizativa do regime de bem-estar no caso europeu ${ }^{\text {. Há outras }}$ distinções do sistema de políticas sociais no Brasil, desde 1995, se comparado à visão clássica social-democrata na Europa, que buscam romper o legado do "deficit 
social". A seguir, apresentam-se algumas características do modelo implantado e suas diferenças diante da visão "pura" do modelo social-democrata europeu.

Em primeiro lugar, a opção estratégica dos governos Fernando Henrique Cardoso (1995-2002) foi, para Draibe (1998), focalizar ações em grupos vulneráveis, no interior dos programas universais, e ampliar o impacto redistributivo para setores de mais baixa renda. A seletividade para grupos mais vulneráveis aumentaria a justiça social com uma maior progressividade de gasto per capita. Com setores da população à margem do mercado de trabalho e incapazes de se protegerem contra todo tipo de risco social, o Estado, antes de universalizar um serviço social, deveria elevar a qualidade de vida desses grupos, pelo menos até a linha da pobreza (BARROS; FOGUEL, 2002). A pobreza como problema estrutural nunca se inseriu na visão social-democrata na Europa, pois o pleno emprego sempre foi a base material e política dos direitos sociais universais.

Combater a pobreza, segundo Barros e Carvalho (2003), passa por reduzir a desigualdade social. Para se atingir esse objetivo, deve-se aumentar a efetividade do gasto social, sem a necessidade de se aumentar o orçamento público. Para os autores, programas focalizados possuem maior efetividade para reduzir a pobreza e são centrais para alterar o perfil da política social brasileira, qualificar o gasto e direcioná-lo aos segmentos que mais necessitam. Para esses autores, ainda há um fosso nos programas sociais que marginalizam os mais pobres no acesso e nos benefícios. Também para Faria (2002), os principais obstáculos para implantar a estratégia de desenvolvimento social são institucionais e organizacionais, apesar de limites econômicos e fiscais. Entre esses fatores, destacam-se a fragmentação institucional e corporativa, elevado custo e ineficiência, interesses da burocracia, de políticos, de provedores de serviços e a estrutura regressiva de benefícios.

Neri (2007) destaca que, a partir do Plano Real, a pobreza e a desigualdade social se reduziram de maneira quase continuada até 2005, beneficiando, sobretudo, os setores mais pobres da população. Ainda que o Plano Real não objetivasse distribuição de renda, e sim estabilidade macroeconômica, geraram-se efeitos positivos para as políticas redistributivas. Com o ambiente econômico mais previsível, a capacidade de planejar políticas públicas ampliou-se. O governo intensificou estratégias focadas nos segmentos mais vulneráveis e de transferência de renda condicionada (Bolsa Escola - 1998/2002 - e Bolsa Família - a partir de 2003). Orientar ações para os mais pobres, porém, não deixa claros os limites temporais da ação pública e a linha de corte entre aspectos compensatórios e estruturais.

Como destaca Neri (2007), as políticas públicas não visam reduzir a desigualdade em si, mas melhorar o nível de bem-estar da população, o que depende da estabilidade econômica e da geração de empregos para atacar a pobreza de modo sustentável. Como, diante das históricas deficiências em desenvolvimento educacional do País, se poderia qualificar a força de trabalho e reduzir sua dependência estrutural de políticas públicas compensatórias? Qual o limite da despesa pública para manter o atendimento a essa clientela sem que seja incorporada na atividade econômica? Distinta foi a experiência, segundo Haggard e Kaufman 
(2008), do Leste Asiático, combinando política educacional e desenvolvimento econômico. Reduzir a desigualdade de renda e gerar empregos formais não só depende do desempenho da economia, mas também das condições de inserção competitiva da força de trabalho. A questão que fica, assim, é se o ataque aos efeitos compensatórios gerará mudanças sustentáveis no longo prazo.

Barros e Foguel (2002) mostram os desafios no acesso e nos benefícios que havia para a população mais pobre auferir dos programas públicos até o final da década de 1990. Para os autores, a maioria dos serviços sociais oferecidos pelo governo federal estava mal focalizada na clientela prioritária, que era mais vulnerável aos riscos sociais. Não seria, assim, necessário ampliar o gasto social para erradicar a pobreza, desde que se direcionasse aos mais pobres para melhorar sua efetividade. Também se poderia combater a pobreza por meio dos programas universais, pois estes não são descontínuos e têm maior qualidade dos serviços. Focalizar o universal e combinar universalidade e seletividade seria, portanto, a estratégia central no combate à pobreza (DRAIBE, 1998).

Um debate com essas características, ao menos no plano normativo, distancia-se do modelo social-democrata, pois a focalização é um conceito estranho a um sistema cujo princípio básico é a universalização dos direitos sociais dos cidadãos. O Brasil possui níveis de desigualdade social e regional que, historicamente, incidem negativamente sobre políticas redistributivas. No Brasil, as políticas sociais, para serem de fato universais no acesso e nos benefícios, precisam enfrentar esse peso histórico e institucional que remete a uma questão que parece importante: Como ampliar os níveis de integração social diante das características estruturais de exclusão social e baixo nível de reconhecimento efetivo dos direitos dos cidadãos? Claro que, com esses programas sociais, parece ter ocorrido uma redução da sua fragmentação e dispersão, melhoria na coordenação intergovernamental e flexibilização regional das ações, tal como Faria (2002) enfatiza, mas não se impedirá a reprodução da pobreza sem a reinserção social produtiva. Por esse motivo, para Draibe (1998), não basta só investir em política social sem uma agenda de desenvolvimento para as áreas mais pobres. Por isso, ampliar a igualdade e equidade na vida coletiva nacional ainda é tarefa inacabada do regime de bem-estar no Brasil.

Como vimos, ainda persiste, no Brasil, uma visão de cidadania que dista, em vários programas, da efetiva universalização no acesso e nos seus benefícios. A efetividade do gasto público nas políticas sociais ainda tem um ajuste de contas a fazer com o legado histórico de exclusão, visando à universalização da cidadania. Nesse caso, parece que as políticas sociais deveriam gerar, segundo Amenta e Skocpol (1986), um efeito de feedback capaz de alterar as politics existentes para que o governo se pergunte acerca dos meios para melhorálas com novas policies. Esse aprendizado político institucional, até o final da década de 1990, ainda esperava que as policies fossem mais universais no seu formato $e$ nas clientelas atendidas.

O segundo aspecto da reforma do sistema de políticas sociais no Brasil pós-1988 foi o desafioparafinanciá-loe regulá-lo.Aprincipal mudança consistiu na descentralização, democratização e participação social como novas formas de gestão. No âmbito 
do governo federal, porém, um problema central foi a coordenação horizontal entre os órgãos que atuam na área social. Essa questão impactou diretamente a efetividade do gasto público, pela superposição de áreas de atuação ou pelo conflito de metas em programas distintos para a mesma clientela. Barros e Carvalho (2003) exemplificam essa situação frisando que as famílias poderiam ser duplamente estimuladas, e de maneira contraditória. Enquanto um programa incentivava a presença na escola, outro oferecia qualificação profissional para reinserção no mercado de trabalho. Parece que essa incapacidade de coordenação intergovernamental não se alterou até o final da década de 1990, pois estímulos desencontrados ainda ocorriam para os públicos dos programas sociais.

A realidade acima apresentada evidencia que o sistema de políticas sociais brasileiro, no período referido, carecia de mecanismos mais efetivos de gestão operacional. Tanto em termos de desenho como de implementação, a tarefa do governo federal como financiador e regulador do sistema não supriu essa lacuna. Como visto anteriormente, o binômio ampliar a equidade e a efetividade dos recursos públicos era considerado central na área social. Para obterem-se avanços nessa direção, contudo, uma gestão mais organizada dos programas, considerando as duplicidades acima referidas, foi uma lacuna não preenchida. Medidas corretivas ou mitigadoras dessa realidade tiveram que esperar até que o cadastro único dos programas sociais fosse implantado.

Afora o esforço de unificação da clientela das políticas sociais, passada a experiência brasileira até o início dos anos 2000, alguns autores sugerem medidas visando gerar maior racionalidade no gerenciamento dos programas. Para Neri (2004), medidas como o crédito social entre governo federal e municípios serviriam para condicionar o repasse de verbas a resultados, e não apenas às exigências de ordem legal. Segundo o autor, se o núcleo da política social são os recursos transferidos da União para os municípios, deve existir um monitoramento que verifique não só a correta aplicação do orçamento, mas, sobretudo, os resultados obtidos pelos mais pobres. Já Barros e Carvalho (2003) tratam da flexibilização dos programas federais às realidades regionais, que demanda maior capacidade de policy learning para realizar ajustes nos programas. Em um país federativo como o Brasil, culturalmente heterogêneo e com clivagens regionais e socioeconômicas profundas, essa é uma questão importante para a gestão das políticas sociais.

De todo modo, a partir de 1995, e em relação à maneira de executar os programas federais, dois vetores foram intensificados: a descentralização de políticas públicas para os municípios e para ONGs. Como frisado anteriormente, tais inovações institucionais não são incorporadas por Esping-Andersen (2000), pois seu modelo se restringe à tríade Estado, Mercado e Família no welfare state.

Analisando a descentralização das políticas públicas, Arretche (2002) mostra que, em países federativos como o Brasil, os municípios têm autonomia política e podem se constituir em pontos de veto. $\mathrm{O}$ governo federal, para contornar tais problemas, criou estratégias de indução política e financeira, variáveis conforme a política social, para a esfera local aceitar novas atribuições. Para a autora, o sucesso da descentralização em políticas como saúde e educação se deve, sobretudo, à capacidade de o governo federal 
garantir incentivos para que os municípios assumam novas responsabilidades. Superados os desafios iniciais, o regime de bem-estar no Brasil passou a ser implantado de maneira descentralizada, cabendo ao governo federal financiar e regular as políticas. Diferentemente do que dizem Haggard e Kaufaman (2008), a reforma das políticas sociais no Brasil foi eficaz, mesmo que o sistema político conviva com veto points na arena federativa.

Uma saída para esse problema, segundo Arretche (2002) argumenta, é que, após a fase de aprovação das leis, se desloca para ogoverno federal a autoridade sobre os conteúdos das políticas. E, nesse momento, as burocracias passam a decidir, independentemente do Legislativo, a tradução das leis em política efetiva por meio de regras de implantação (como as NOBs para a saúde). A ação da burocracia no contexto de descentralização das políticas sociais, combinada com arenas federativas de decisão, tal como a Comissão Tripartite para a Saúde, gerou um peculiar desenho institucional. O sistema de políticas sociais, além de ser descentralizado, criou mecanismos de controle resultantes das pressões democratizantes da sociedade e do policy learning das burocracias (ARRETCHE, 2002; AMENTA; SKOCPOL, 1986).

Distintamente do modelo europeu, não se instalou um modelo de peak associations (sindicatos e partidos) que decidem políticas de bem-estar em conjunto com o governo, tal como a experiência social-democrata europeia. No Brasil, aprofundaram-se a descentralização da execução e a gestão de serviços sociais para as localidades. Ao mesmo tempo, criaramse mecanismos federativos de articulação que incorporaram vários atores e interesses que podem atuar como veto points. Mais uma vez, o desenho político-institucional do welfare state europeu parece ter sido diferente: as políticas sociais eram ofertadas de maneira centralizada.

No Brasil, a descentralização foi coerente com a maior universalização e ampliação do acesso e benefícios a amplas parcelas da população. A descentralização foi o formato político e administrativo na organização federativa do regime de bem-estar social no Brasil. Não se encontram referências a um processo com essas características em Esping-Andersen (2000) para propor, por exemplo, a reorganização do welfare state diante dos novos desafios colocados pela economia pós-industrial. No limite, o que se depreende da visão desse autor seria uma descentralização para a sociedade, quando sugere que as famílias poderiam ser atores relevantes, visando garantir direitos e manter a solidariedade social.

Devem ser apontados, contudo, os problemas da visão que associa descentralização com mais democracia no plano local, ampliação da equidade, redução do clientelismo e do desvio de recursos públicos destinados à área social. A organização de conselhos de políticas públicas foi, segundo Draibe (1998), uma das fortes inflexões para articular interesses da sociedade na formulação de políticas e tomada de decisões. A forma "conselhos" municipais de políticas públicas deveria ser capaz de exercer controle social sobre - poder público e canalizar energias democráticas. Conforme Draibe (1998), porém, esses fóruns foram limitados em controlar as ações dos governantes, em face de sua dependência do poder público e de sua baixa capacidade técnica. Diante da histórica relação entre clientelismo e assistencialismo no Brasil, é plausível 
admitir-se uma distorção na concepção democrática dos conselhos diante da influência dos governos locais, sobretudo por se tratar de instâncias que autorizam ou vetam o uso de recursos públicos.

Outra inovação da descentralização na década de 1990 foi ampliar os canais de participação em relação à sociedade civil. Para Barros e Carvalho (2003), a participação comunitária ajustou melhor os programas às necessidades locais e aumentou sua eficácia operacional. A descentralização e a participação da sociedade foram, como destacado por Draibe $(1994 ; 1998)$ e Fagnani (1997), formas de contrarrestar a centralização decisória que vigorou durante - regime militar nas políticas sociais. Mecanismos de parceria com a sociedade civil, o apoio a ONGs e o reforço a entidades com a presença direta da clientela, como Associações de Pais e Mestres nas escolas, passaram a compor o cardápio de opções governamentais para descentralizar as políticas sociais. Ao final da década de 1990, com os programas sociais descentralizados para os governos subnacionais, sobretudo para municípios, as inovações institucionais passam a ser a aproximação com a sociedade civil para ampliar a capacidade de atendimento das políticas públicas.

Em setores como saúde, educação e assistência social, a descentralização e a participação da sociedade buscaram ampliar a oferta de serviços para responder aos limites da provisão diretamente estatal. A descentralização de serviços sociais configurou o que Bresser-Pereira (1997) definiu como um modelo de provisão "público, mas não estatal." Fortaleceu-se uma "compreensão de que o Estado, sem abdicar de sua responsabilidade e sua identidade própria, não pode nem deve, sozinho, tudo fazer, fórmula que se traduz no reforço das suas parcerias com os setores privados não-lucrativos [...]" (DRAIBE, 1998, p. 119). ONGs passaram, assim, a executar serviços públicos, por exemplo, na assistência social (convênios para serviços de creches ou cuidados com a terceira idade) e na saúde (equipes de Programa Saúde da Família e agentes comunitários).

Quando confrontado com o provimento de serviços do modelo social-democrata, estatal e centralizado, tal como concebido por Esping-Andersen (2000), a configuração adotada no Brasil é inovadora. Pelo menos duas ressalvas, porém, podem ser feitas: a) ineficaz controle gerencial do Estado para avaliar como o recurso público é utilizado e se os serviços ofertados pela ONG são eficazes e condizem com o perfil da demanda; b) o repasse de ações como formular e planejar políticas públicas às ONGs pode desestimular a construção de burocracias mais qualificadas, especialmente no nível local, se contratam tais serviços.

Emblemático dessa concepção de parceria com a sociedade foi o programa Comunidade Solidária, que, para Draibe (1998), focouse no combate à pobreza. Suas inovações foram ações sociais integradas, com delimitação territorial da clientela mais pobre e apoio do setor privado e filantrópico. Buscava-se garantir, segundo Draibe (1998), uma concepção de direitos sociais universalizantes e afastada do clientelismo. Por outro lado, diante do desenho do welfare state mais universalizante em que o Estado é o provedor central de serviços sociais, - programa Comunidade Solidária tem distinções relevantes. Sua natureza focada nas localidades mais carentes, selecionadas 
segundo o Índice de Desenvolvimento Humano Municipal (IDH-M), talvez não tenha gerado um programa em bases universais. Ademais, a prioridade no combate à pobreza talvez não tenha pautado o tema dos direitos sociais como prioridade, a exemplo da centralidade que esse assunto assumiu nos regimes de bem-estar na Europa.

Tais características desse programa distam do modelo social-democrata, pois a "luta de classes democrática" e a definição das políticas de combate aos riscos sociais têm no governo, nos empresários e nos sindicatos os atores centrais. As iniciativas como o programa Comunidade Solidária voltaram-se para os públicos não organizados e mais afetados pela exclusão social. Coube ao Estado menos arbitrar a "luta de classes democrática" e mais ocupar os vazios sociais e territoriais não preenchidos pelo desenvolvimento econômico e social no Brasil. De outra parte, no caso clássico do welfare state, embora seja o Estado o provedor de serviços, os sindicatos de trabalhadores sempre atuaram como partes interessadas e atores importantes na construção dos pactos entre empresas e o poder público. A ênfase na participação da sociedade e na constituição de um espaço com a presença do poder público, proposto pelo programa Comunidade Solidária, não se compara, assim, ao tripé sindicatosgovernos-empresas do regime de bem-estar europeu.

\section{Notas Finais: a Evolução do Regime de Bem-estar Brasileiro até a Década de 1990}

Foi frisado, no início do texto, o objetivo de apresentar três períodos históricos do desenvolvimento do regime de bem-estar social no Brasil para destacar suas características centrais e especificidades diante do modelo social-democrata europeu. Para apoiar a construção de hipóteses para futuras pesquisas, o artigo buscou mostrar que a evolução dos sistemas de políticas sociais, comparando a realidade brasileira e o tipo social-democrata de welfare state, seguiu diferentes trajetórias. A opção adotada, de apresentar de maneira comparada três grandes períodos, serviu para essa finalidade, pois fica mais nítida a distinção de caminhos que sofreram os sistemas de políticas sociais nas duas realidades. Mais do que distintos, caminhos que, nos três momentos, se opõem nas suas opções políticas. Ainda que a prioridade tenha sido o período posterior a 1990, colocar o tema em perspectiva mais ampla entre 1930 e o início do século XXI ajuda a mostrar as mudanças que se processaram e seu curso provável. Para fins de conclusão, nada mais que uma síntese para alinhar problemas de pesquisa, uma observação geral para cada um dos três períodos ajuda nesse objetivo.

Em primeiro lugar, em relação ao período 1930-1964, analisa-se o legado negativo do "realinhamento crítico" das opções adotadas pelas elites políticas em face do modelo societário ancorado na cidadania regulada. Os efeitos desse desenho político-institucional geraram atrasos significativos na expansão da cidadania em bases mais universais. Essa expansão, de maneira lenta e contraditória, iniciou ainda no regime militar, mas apenas a partir da segunda metade dos anos 1980 começou a ser revertida. No Brasil, o tema dos direitos sociais ficou truncado diante de uma visão excludente de amplas parcelas da população não inseridas em termos produtivos no mercado de trabalho. O Estado, no Brasil, não se responsabilizou pela oferta de serviços para a população marginalizada que não estivesse 
representada pelo modelo de cooptação política e social entre sindicatos, governo e empresas.

$\mathrm{Na}$ Europa, nesse mesmo período, consolidou-se um padrão de universalização de direitos sociais e de cidadania nacional distinto da estratificação social determinada pelo mercado de trabalho e pela ocupação funcional. A tríade sindicatos, empresas e Estado gerou um arranjo político e institucional em bases mais generosas ao garantir amplo acesso à sociedade para as políticas sociais. O período pós-1945 foi marcado por uma crescente ampliação das franquias para setores sociais acessarem as ofertas de welfare state, independentemente de sua posição na esfera produtiva como assalariado. O "realinhamento crítico" que houve com a organização do modelo socialdemocrata foi, assim, a constituição de um pacto social em bases cada vez mais universalizantes em termos de direitos sociais.

Em segundo lugar, no regime militar brasileiro, expansão e consolidação do Estado de bem-estar social não se valeram de nenhuma mediação política para construir consensos coletivos sobre o modelo de solidariedade social a ser implantado. A burocracia tornou-se um ator privilegiado na definição de políticas e interlocutores sociais, especialmente no setor privado. Em vez do pacto entre governo e sindicatos para gerar políticas sociais, tal como no modelo social democrata europeu, no Brasil, fortaleceramse os vínculos entre os interesses da burocracia e das empresas privadas. Antes de reforçar políticas sociais mais universalizantes que, na experiência social democrata na Europa, adquiriram sua feição mais acabada nos anos 1970, no Brasil, o regime de bem-estar teve outra característica. O modelo econômico concentrador de renda e a desigualdade social foram marcas centrais, apesar da expansão das políticas sociais.

No modelo social-democrata europeu, a política ocupou um lugar de destaque como mediadora de acordos entre capital, trabalho e poder público, com destaque para as peak associations, por sua natureza de representação ampla e corporativa. A face econômica do capitalismo não se desenvolveu, assim, em detrimento das possibilidades de estender uma rede de direitos sociais que reduzisse os efeitos deletérios de uma lógica mais pautada pela concentração de renda. O Estado, em vez de ser uma instituição e um ator político voltado a garantir as bases da exploração econômica e a repressão da representação política das classes trabalhadoras em seus sindicatos, atuou como promotor de consensos sociais. Nesse período, portanto, o welfare state atingiu seu ápice como um sistema generoso de políticas sociais em bases ainda solidárias e universais em direitos.

Em terceiro lugar, após 1994, comparar o modelo social democrata europeu com as políticas sociais no Brasil adquire outra conotação. Na Europa, o desafio, segundo Esping-Andersen (2000), era recriar as bases do modelo societário universalizante em face das mudanças econômicas e sociais, notadamente a desintegração familiar. Mudanças na base econômica da sociedade (alteraçãodasbasestecnológicas deprodução, novos players no mercado mundial etc.) foram aspectos que, gradativamente, minaram os pilares materiais do modelo. A ênfase na "desmercadorização" como garantia de direitos universais amparados pelo Estado foi cedendo lugar a estratégias de sobrevivência 
social menos dependentes do poder público, com o protagonismo assumido pelas famílias. A esfera privada e doméstica, garantia do modelo ideal do welfare state centrado no mercado de trabalho para os homens e priorizado como espaço de construção da vida familiar, sofreu mudanças profundas: em primeiro lugar, diante das alterações no mercado de trabalho e do crescimento do desemprego estrutural, as mulheres ampliaram sua inserção na oferta de mão de obra; em segundo lugar, a assunção de novas responsabilidades, antes assumidas pelo Estado na garantia de direitos sociais, alterou a dinâmica de vida desse grupo social.

No Brasil, o regime de bem-estar social passou a se pautar por valores mais compreensivos em defesa dos direitos e da cidadania, com um sistema mais generoso de políticas sociais. Ainda assim, debates como a focalização de programas para combater a pobreza e a desigualdade social são estranhos à visão social-democrata na Europa. Isso porque esse modelo compreende que o welfare state é, acima de tudo, um sistema de políticas que se sustenta em cidadãos com direitos sociais reconhecidos e em bases universais. Ainda que as políticas sociais encetadas pelo Estado visassem ampliar direitos e o acesso a segmentos sociais marginalizados, o descolamento do mercado de trabalho ainda se manteve. A opção "pelo social" adotada no Brasil depois da Constituição de 1988 esteve longe de criar um sistema ancorado em arranjos clássicos entre capital, trabalho e poder público. Coube ao Estado o papel de protagonista, visando implantar políticas sociais que combinassem compensação, focalização e universalização de direitos para mitigar problemas estruturais de desigualdade social e incapacidade de inserção produtiva. A base econômica desse novo ciclo de políticas sociais no Brasil esteve longe de criar pactos assentados na base econômica, a despeito de ter sido uma opção mais justa da sociedade brasileira em direção a padrões menos predatórios de cidadania.

\section{Referências}

AMENTA, E.; SKOCPOL, T.States and social policies. Annual Review of Sociology, Palo Alto, n. 12, p. 131-157, 1986.

ARRETCHE, M. T da S. Federalismo e relações intergovernamentais no Brasil: a reforma de programas sociais. Dados: Revista de Ciências Sociais, Rio de Janeiro, v. 45, n. 3, p. 431-458, 2002.

BARROS, R. P. de; CARVALHO, M. de. Desafios para a política social brasileira. IPEA, Rio de Janeiro, n. 985, p. 1-23, 2003.

BARROS, R. P. de; FOGUEL, M. N. Focalização dos gastos públicos sociais e erradicação da pobreza no Brasil. In: HENRIQUES, R. (Org.). Desigualdade e pobreza no Brasil. Rio de Janeiro: IPEA, 2002. p. 719-739.

BENDIX, R. Construção nacional e cidadania: estudos de nossa ordem social em mudança. São Paulo: Edusp, 1996.

BRESSER-PEREIRA, L. C. Una reforma gerencial de la administración pública en Brasil. Revista Reforma y Democracia, Caracas, v. 9, p. 1-27, 1997.

CARVALHO, J. M. Cidadania no Brasil: o longo caminho. Rio de Janeiro: Civilização Brasileira, 2006.

DRAIBE, S. M. As políticas sociais do regime militar brasileiro: 1964-84. In: SOARES, G. 
A. D.; SOUZA, D'A. M. C. (Org.). 21 anos de regime militar: balanços e perspectivas. Rio de Janeiro: Fundação Getulio Vargas, 1994. p. 271-315.

Brasil, ano 90: as políticas sociais no marco das reformas estruturais. Campinas: Cepal, 1998.

A política social no período $\mathrm{FHC}$ e o sistema de proteção social. Tempo Social, São Paulo, v. 15, n. 2, p. 63-101, 2003.

DRAIBE, S. M.; AURELIANO, L. A especificidade do welfare state brasileiro. In:_. Economia e desenvolvimento. Brasília: MPAS/Cepal, 1989.

DRAIBE, S. M.; RIESCO, M. Estado de bienestar, desarrollo económico y ciudadania: algunas lecciones de la literatura contemporánea, Serie Estúdios y Perspectivas, México, D.F., n. 55, p. 1-58, 2006.

Esping-Andersen, G. As três economias políticas do welfare state. Lua Nova, São Paulo, n. 24, p. 85-116, 1990.

\section{Social foundations of} postindustrial economies. Oxford: Oxford University, 2000.

FAGNANI, E. Política social e pactos conservadores no Brasil: 1964-92. Cadernos Fundap, São Paulo, p. 59-102, 1997.

FARIA, V. E. Reformas institucionales y coordinación gubernamental en la proteción social de Brasil. Revista de la Cepal, Santiago, n. 77, p. 7-24, 2002.

Haggard, S.; Kaufman, R. Development, democracy and welfare states: Latin American, East Asia and Eastern Europe. Princeton: Princeton University, 2008.

Lindblom, C. O processo de decisão política. Brasília: Universidade de Brasília, 1981.

Marshall, T. H. Política social. Rio de Janeiro: Zahar, 1965.

. Cidadania, classe social e status. Rio de Janeiro: Zahar, 1967.

NERI, M. Focalização, universalização e transferências sociais. Revista Econômica da UFF, Rio de Janeiro, v. 5, n. 1, p. 163-170, 2004.

Pobreza e políticas sociais na década da redução da desigualdade. Nueva sociedad, Caracas, especial em português, Brasil: a caminho da equidade, out. 2007. Disponível em: <http://www.nuso.org/upload/ portugues/2007/CortesNeri.pdf>. Acesso em: 30 abr. 2009.

Santos, W. G. Cidadania e justiça: a política social na ordem brasileira. Rio de Janeiro: Campus, 1979.

Crise e castigo: partidos e generais na política brasileira. São Paulo: Vértice; Rio de Janeiro: Revista dos Tribunais; Rio de Janeiro: IUPERJ, 1987.

\section{Notas}

1. O autor agradece os pareceristas anônimos por seus valiosos comentários, que contribuíram para elucidar pontos fundamentais deste artigo. 2. Ainda que Draibe e Aureliano (1989) enfatizem que, após 1930, a educação se tornou uma 
questão nacional com sua centralização na União, o sistema era marcadamente urbano, embora, até $1960,55 \%$ da população vivesse no campo e, até $1950,51,6 \%$ da população fosse analfabeta (SANTOS, 1987).

3. Como a União legislava sobre a cidadania no tocante ao exercício da profissão reconhecida para atividades técnico-científicas e liberais e, por meio do direito do trabalho, regulava as demais profissões, tem-se, assim, a dimensão do monopólio estatal sobre o acesso da população à sociedade organizada e seus direitos sociais (SANTOS, 1987).

4. A comparação com a Inglaterra é menos histórica e mais da forma como se processou a luta política dos trabalhadores e dos sindicatos e sua incorporação no interior da cidadania nacional.

5. A relação entre ampliação do aparato burocrático estatal e a privatização do espaço público é apresentada em Fagnani (1997). Para o autor, a centralização decisória das políticas sociais deu-se coma construção de grandes estruturas burocráticas como o Sistema Financeiro de Habitação (SFH), - Sistema Nacional de Previdência e Assistência Social (Sinpas) e o Sistema Financeiro de Saneamento (SFS). Esses órgãos formulavam e implantavam políticas públicas com autonomia decisória e recursos financeiros. Os vínculos entre a burocracia e os interesses privados manifestaramse em diversas políticas sociais, sem considerar critérios de relevância e foco nas clientelas mais necessitadas. Deu-se pouca importância à capacidade de sustentação no longo prazo, para não inviabilizar os mecanismos de financiamento que poderiam produzir vácuos em diversas áreas de ação do Estado, como foi o caso da habitação e saneamento básico que, só na década de 1990 recuperaram o fôlego para investimentos.

6. Será utilizada a expressão sistema de política social para discutir, no caso brasileiro, o regime de bem-estar social, como tradução do que a literatura chama de welfare state. Essa opção também se deve ao fato de, conforme EspingAndersen (1990), existirem três tipos de welfare state na Europa, mas o Brasil não se encaixa em nenhum desses.

7. Para Draibe (2003), no primeiro governo Fernando Henrique Cardoso (1995-1998), a base social democrata dos programas teve três eixos: direito social, igualdade de oportunidades e proteção aos grupos mais vulneráveis. Os serviços sociais básicos ampliaram seu aspecto redistributivo, a descentralização e a participação social. $O$ combate à pobreza deu-se por meio do programa "Comunidade Solidária,' em parceria com estados, municípios, iniciativa privada e a sociedade. A principal diferença do segundo mandato (1999-2002) foram os programas de transferência direta de renda focada nas famílias mais pobres, para melhorar a proteção contra situações de risco social.

8. Parece que essa seria uma estratégia de sobrevivência familiar alternativa às regras de mercado e sua crescente exclusão da força do trabalho na sociedade pós-industrial mencionada pelo autor.

9. Mesmo que na Europa prevaleçam democracias parlamentaristas, não parece que a descentralização de políticas públicas seja uma característica intrínseca de países federalistas. 